\title{
Decomposition of Trichloroethylene by Microwave-Induced Ar Plasma Generated from SiC Ceramics under Atmospheric Pressure
}

\author{
Yasuhiro SHIMIZU, Kazuya OGAWA, Yuji TAKAO ${ }^{\dagger}$ and Makoto EGASHIRA*
}

Received June 24, 1998 ; Accepted July 17, 1998

\begin{abstract}
Behavior of microwave-induced Ar plasma generated from $\mathrm{SiC}$ ceramics under atmospheric pressure in different flowing gas mixtures and decomposition behavior of thrichloroethylene by the microwave-induced Ar plasma have been investigated systematically. Although the behavior of the microwave-induced Ar plasma was varied with the composition of the flowing gas mixture, the plasam could be generated even in the flowing Ar containing $0.64 \%$ trichloroethylene and $9.0 \% \mathrm{O}_{2}$. In addition, $0.64 \%$ tricholoethylene balanced with $\mathrm{Ar}$ at a flow rate of $500 \mathrm{~cm}^{3} \mathrm{~min}^{-1}$ could be completely decomposed by the addition of $9.0 \% \mathrm{O}_{2}$ by means of the microwave-induced Ar plasma of a power above $90 \mathrm{~W}$, without producing any partial decomposition products as well as $\mathrm{CO}$. In contrast, a large amount of $\mathrm{CO}$ was formed by thermal decomposition of trichloroethylene even at a temperature as high as $900^{\circ} \mathrm{C}$. Therefore, the decomposition by the Ar plasma is confirmed to offer several advantages, compared with the thermal decomposition, with respect to complete oxidation, concentration of partial decomposition products and energy efficiency.
\end{abstract}

\section{INTRODUCTION}

Much attention has been denoted to effective decomposition of gaseous pollutants, such as chlorofluorocarbons, carbon tetrachloride and trichloroethylene, by plasma chemical processing from the viewpoint of global environmental issues. ${ }^{1-6)}$ To decompose these pollutants in large quantities, stable plasma should be generated under an atmospheric environment, but this requires relatively high power of several tens $\mathrm{kV}$. Under a reduced environment, such stable plasma can be generated with relatively low power. However, a large vacuum facility is indispensable, and such process limits decomposition

Department of Materials Science and Engineering, Faculty of Engineering,

'Department of Environmental Studies, Faculty of Environmental Studies,

Nagasaki University (1-14 Bunkyo-machi, Nagasaki 852-8521, Japan)

Key Words : Microwave-Induced Ar Plasma, SiC, Trichloroethylene, Decomposition efficiency. To realize further expansion of this plasma chemical processing in decomposing these pollutants, therefore, improvement of the energy efficiency for the plasma generation under an atmospheric environment is of importance.

We found that white and woolly $\beta$-SiC whiskers fabricated by thermal decomposition of sulfercontaining silicon oils exhibited amazingly high electrical conductivity in the range of $10^{2}-10^{3} \mathrm{~S} \mathrm{~cm}^{-1}$ at room temperature. ${ }^{7}$ These whiskers were red heated and then emitted $\mathrm{N}_{2}$ plasma discharge in flowing air under atmospheric pressure upon irradiation of 2.45 $\mathrm{GHz}$ microwave. Then, fluorocarbons and trichloroethylene could be decomposed by such microwaveinduced (MI) $\mathrm{N}_{2}$ plasma under atmospheric pressure ${ }^{78)}$ However, the contribution of the thermal decomposition over the heated whiskers was suggested to be significant under MI $\mathrm{N}_{2}$ plasma in air. In contrast, a strong bluish Ar plasma streak was generated from the whiskers upon irradiation of microwave under flowing Ar under atmospheric pressure without being red heated. Our additional 
study has revealed that the MI Ar plasma was more advantageous in decomposing trichloroethylene with less partial decomposition products than the $\mathrm{MI} \mathrm{N}_{2}$ plasma. ${ }^{9)}$ However, no systematic study was carried out with respect to the effects of the trichloroethylene, oxygen and water vapor contents in the Ar flowing on the decomposition behavior.

The present study explores first the ability of SiC ceramics for generating MI Ar plasma under atmospheric pressure. Then, the performance of the MI Ar plasma for the decomposition of trichloroethylene was evaluated under different conentrations of trichloroethylene, oxygen and water vapor.

\section{EXPERIMENTAL}

2.1 Generation and characterization of $\mathrm{MI} \mathrm{Ar}$ plasma

A microwave power generator (MR-200, Unidux), capable of modulating the output power from 15 to $200 \mathrm{~W}$ at $2.45 \mathrm{GHz}$, equipped with a box cavity was used as a microwave source. SiC ceramic pieces prepared by crushing a siliconit heating element (Siliconit Konetsu Kogyo Co., Ltd) were used as a trigger of the MI Ar plasma. Several pieces of the $\mathrm{SiC}$ ceramics of $2-3 \mathrm{~mm}$ in size were set in a quartz glass tube (12 $\mathrm{mm}$ in diameter) in an atmospheric flow apparatus located in the cavity. The emission spectrum of the MI Ar plasma in the flowing Ar containing $0.11 \%$ trichloroethylene at a flow rate of $500 \mathrm{~cm}^{3} \mathrm{~min}^{-1}$ was analyzed by Multi Channel Photo Detector (MCPD-1000, Otsuka Electronics). The effect of the addition of oxygen and water vapor on the MI Ar plasma behavior was also examined at a total flow rate of $500 \mathrm{~cm}^{3} \mathrm{~min}^{-1}$.

\subsection{Decomposition of trichloroethylene by MI Ar plasma}

Decomposition bahavior of trichloroehylene was measured under atmospheric pressure by employing the same flow apparatus as above. A gaseous mixture of trichloroethylene, oxygen and water vapor balanced with $\mathrm{Ar}$ was fed at a flow rate of $500 \mathrm{~cm}^{3}$ $\min ^{-1}$ to the quartz glass tube located in the cavity. The composition of the feed gas was $0.11-0.64 \%$ trichloroethylene, $0-9.0 \% \mathrm{O}_{2}$ and $0-0.77 \% \mathrm{H}_{2} \mathrm{O}$. Variations in conversion of trichloroethylene and in concentration of partial decomposition products with the microwave power consumed were analyzed by gas chromatography (GC-14B, Shimadzu) and gas chromatography-mass spectroscopy (QP-5000, Shimadzu).

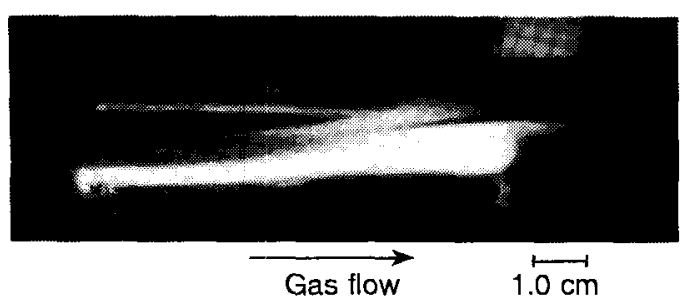

(a)

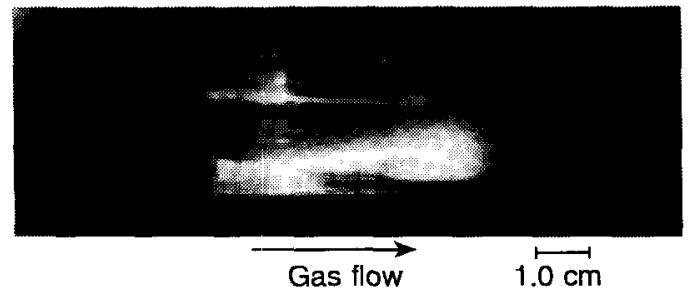

(b)

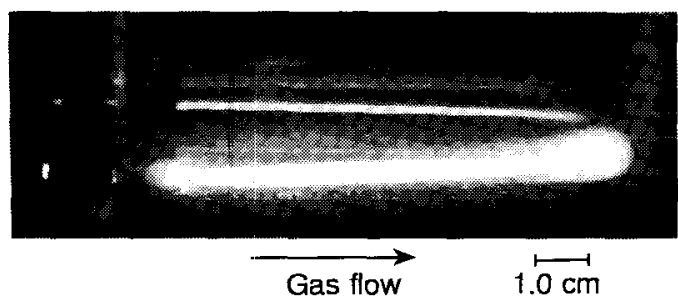

(c)

Fig. 1 Photographs of MI Ar plasma generated from $\mathrm{SiC}$ ceramics in (a) flowing Ar containing $0.11 \%$ trichloroethylene (basic flowing), (b) basic flowing plus $3.0 \% \mathrm{O}_{2}$, and (c) basic flowing plus $0.38 \%$ water vapor (microwave power: $100 \mathrm{~W}$ ).

\subsection{Thermal decomposition of trichloroethylene}

For comparative purpose, thermal decomposition of trichloroethylene was conducted by employing the same flow apparatus and under the same flow condition. The gas composition after the thermal decomposition over the $\mathrm{SiC}$ ceramics heated by an electric furnace was analyzed. The effect of the oxygen and water vapor addition was also tested.

\section{RESULTS AND DISCUSSION}

\subsection{Characterization of MI Ar plasma generated from SiC ceramics}

A streak of a strong, long and narrow bluish white light, like phosphorescence, was observed in the down stream from the $\mathrm{SiC}$ ceramics upon irradiation of microwave in flowing pure $\mathrm{Ar}$, as reported for the case using SiC whiskers as the trigger. ${ }^{8,9)}$ A streak of light 
could also be generated from the $\mathrm{SiC}$ ceramics even in the flowing Ar containing $0.11 \%$ trichloroethylene, as shown in Fig. 1(a). Hereafter this flowing will be referred as the basic flowing. The streak was generated when the microwave power absorbed by the $\mathrm{SiC}$ ceramics was beyond a threshold value, which was dependent on the surrounding atmosphere. Length of the streak was about $8 \mathrm{~cm}$ under the condition of the present study, but the color was rather greenish compared with that in the pure flowing Ar. The emission spectrum measured in the basic flowing is shown in Fig. 2(a). A lot of sharp peaks observed in the range of $700-850 \mathrm{~nm}$ were all assigned to the emission peaks of Ar atoms based on the $4 s-4 p$ electron transition. Thus, the streak of light is confirmed to be the MI Ar plasma. This fact confirms again our previous finding ${ }^{9}$ that materials exhibiting high electrical conductivity generate MI Ar plasma, and that the MI Ar plasma can be maintained even in an atmosphere containing gases which have a tendency to produce negative ions upon decomposition. Additional peaks were observed in the range of $300-550 \mathrm{~nm}$ and were assigned to emission peaks of $\mathrm{C}$ atoms, as shown in Fig. 2(a). This fact suggests that trichloroethylene can be decomposed to constituent atoms in the MI Ar plasma. Since $\mathrm{O}_{2}$ was not involved in the basic flowing, formation of soot was observed in the downstream of the MI Ar plasma after the decomposition of trichloroethylene in the flowing Ar.

Color of the MI Ar plasma streak became reddish and length of the streak was shortened by the addition of 3.0\% $\mathrm{O}_{2}$ to the basic flowing, as shown in Fig. 1(b). Besides the emission peaks of Ar atoms, a sharp peak around $777 \mathrm{~nm}$ was newly observed in the spectrum of the plasma, as shown in Fig. 2(b), and was assigned to an emission peak of $\mathrm{O}$ atoms. Furthermore, emission peaks of $\mathrm{C}$ atoms were disappeared, suggesting the oxidation of $\mathrm{C}$ atoms in the presence of $\mathrm{O}_{2}$.

Addition of $0.38 \%$ water vapor, instead of $3.0 \% \mathrm{O}_{2}$, to the basic flowing highlighted bluish color of the MI Ar plasma. In contrast to the case of $\mathrm{O}_{2}$, the length of the MI plasma streak remained almost unchanged by the addition of $0.38 \%$ water vapor, as shown in Fig. 1(c). Under this condition, intensity of emission peaks of $\mathrm{C}$ atoms became lower than those in Fig. 2(a), but the emission peak of $O$ atoms could not be observed, as shown in Fig. 2(c). These results imply that water vapor in the MI Ar plasma acts as a source

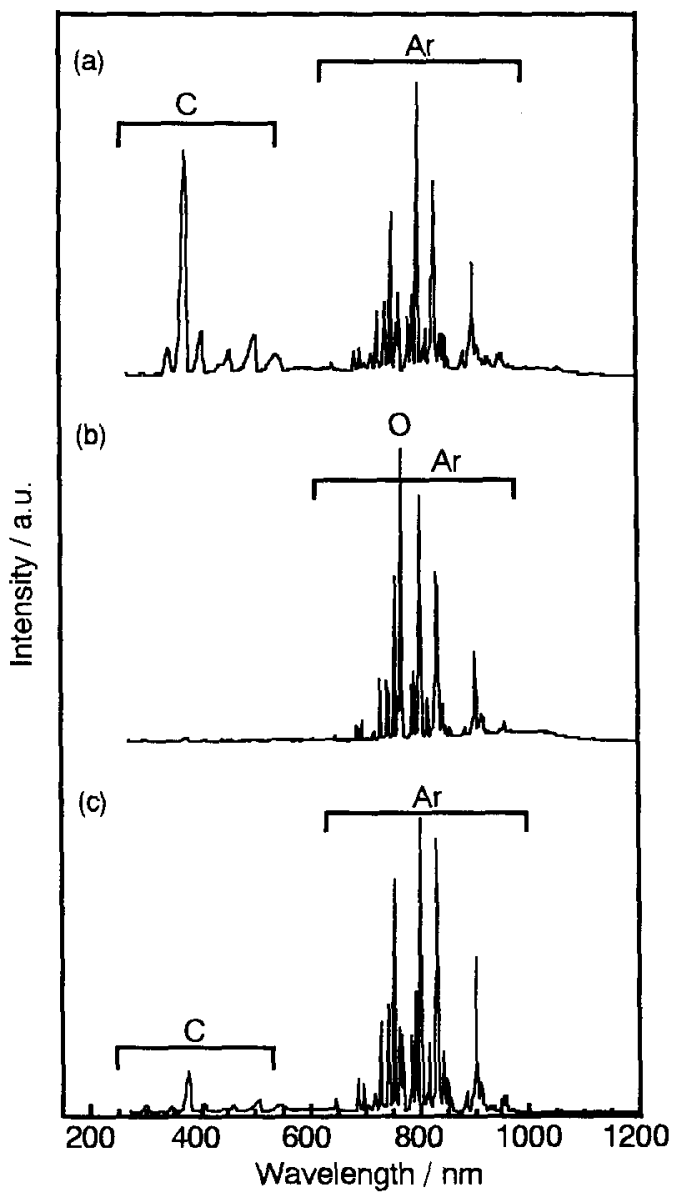

Fig. 2 Spectra of MI Ar plasma generated from $\mathrm{SiC}$ ceramics in (a) flowing Ar containing $0.11 \%$ trichloroethylene (basic flowing), (b) basic flowing plus $3.0 \% \mathrm{O}_{2}$, and (c) basic flowing plus $0.38 \%$ water vapor (microwave power: $100 \mathrm{~W}$ ).

of $\mathrm{O}$ atoms to oxidize $\mathrm{C}$ atoms, but as a weak oxidizing agent.

The length of the MI Ar plasma streak decreased to about $4 \mathrm{~cm}$ with the addition of $9.0 \% \mathrm{O}_{2}$ to the basic flowing. Similar behavior was observed with increasing the concentration of trichloroethylene in the basic flowing. Such a phenomenon is undoubtedly casued by shorter lifetime of the MI Ar plasma under higher concentration of negative ions. Nevertheless, a MI Ar plasma streak of about $3 \mathrm{~cm}$ in length could be generated even in the flowing Ar containing 0.64\% trichloroethylene and $9.0 \% \mathrm{O}_{2}$. 


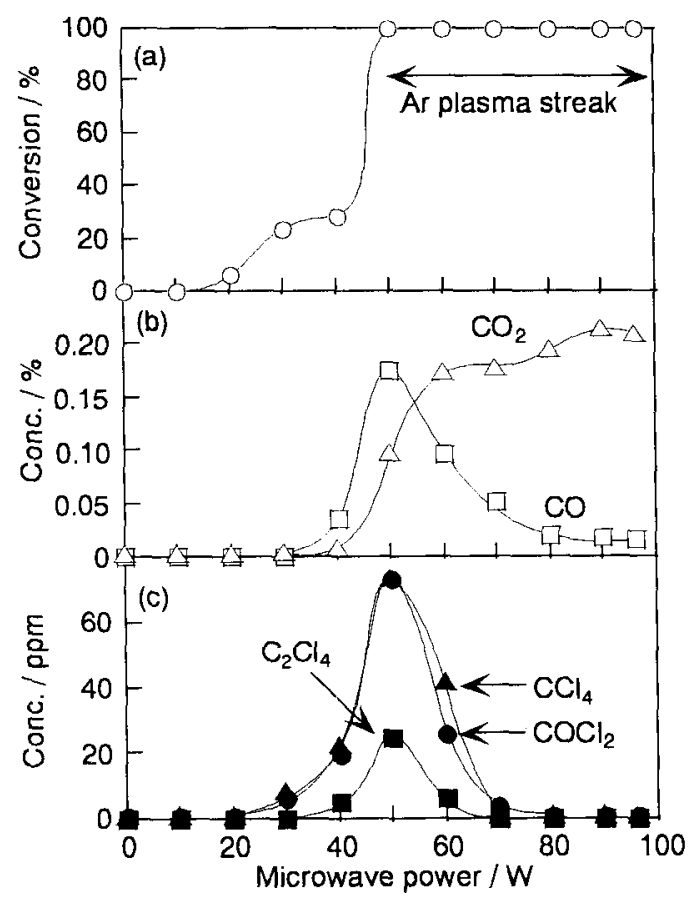

Fig. 3 Variations in (a) conversion of trichloroethylene and in (b) and (c) concentration of partial decomposition products in the MI Ar plasma decomposition with the microwave power absorbed (feed gas: flowing Ar containing $0.11 \%$ trichloroethylene and $3.0 \% \mathrm{O}_{2}$ ).

\subsection{Decomposition of trichloroethylene by MI Ar plasma}

3.2.1 Decomposition behavior of trichloroethylene under an atmosphere containing $\mathrm{O}_{2}$

Flowing Ar containing $0.11 \%$ trichloroethylene and $3.0 \% \mathrm{O}_{2}$ was first used as a feed gas. Figure 3 shows variations in conversion of trichloroethylene and in concentration of partial decomposition products with the microwave power absorbed. Although the $\mathrm{MI} \mathrm{Ar}$ plasma streak could not be generated in the microwave power range of $20-40 \mathrm{~W}$, the conversion increased gradually with an increase in the microwave power, as shown in Fig. 3. Under this feed gas flowing, the MI Ar plasma streak started to generate at a microwave power of $50 \mathrm{~W}$, and then the conversion abruptly attained $100 \%$. The plasma streak and the $100 \%$ conversion level held at the powers higher than above $50 \mathrm{~W}$. The concentration of partial oxidation and decomposition products, such as $\mathrm{CO}, \mathrm{COCl}_{2}, \mathrm{CCl}_{4}$ and $\mathrm{C}_{2} \mathrm{Cl}_{4}$, reached their maxima at $50 \mathrm{~W}$, and then

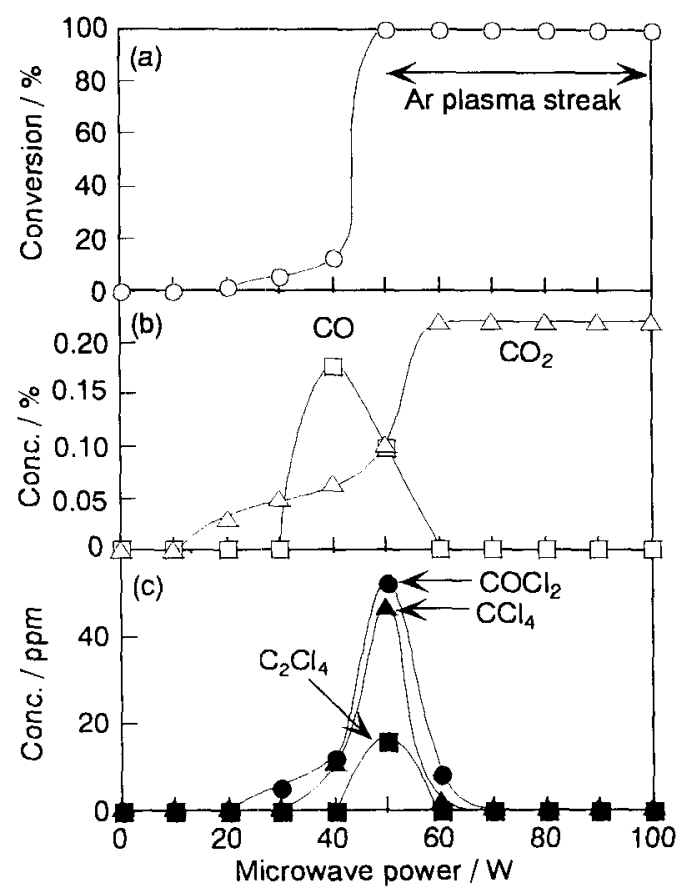

Fig. 4 Variations in (a) conversion of trichloroethylene and (b) and (c) concentration of partial decomposition products in the MI Ar plasma decomposition with the microwave power absorbed (feed gas: flowing Ar containing $0.11 \%$ trichloroethylene and $9.0 \% \mathrm{O}_{2}$ ).

decreased with increasing the microwave power, as shown in Figs. 3(b) and 3(c). On the other hand, the concentration of $\mathrm{CO}_{2}$ increased with an increase in the microwave power above $40 \mathrm{~W}$, and then reached an almost steady-state value above $90 \mathrm{~W}$. The concentration of $\mathrm{CCl}_{4}, \mathrm{C}_{2} \mathrm{Cl}_{4}$, and $\mathrm{COCl}_{2}$ became negligibly small above $80 \mathrm{~W}$, but a small amount of $\mathrm{CO}$ was detected even at a power as high as $90 \mathrm{~W}$. Thus, it is revealed that the $3.0 \% \mathrm{O}_{2}$ addition is not enough to achieve complete oxidation of trichloroethylene under the present experimental conditions.

Addition of $9.0 \% \mathrm{O}_{2}$ led to an improvement in decomposition behavior of trichloroethylen, as shown in Fig. 4. The MI Ar plasma could be generated above $50 \mathrm{~W}$, irrespective of the higher $\mathrm{O}_{2}$ concentration. The concentration of $\mathrm{CO}_{2}$ reached a steadystate value and $\mathrm{CO}$ was rarely detected above $60 \mathrm{~W}$, while the concentration of $\mathrm{CO}$ reached its maximum at $40 \mathrm{~W}$, as shown in Fig. 4(b). In addition, other partial decomposition products were not detected above $70 \mathrm{~W}$, 


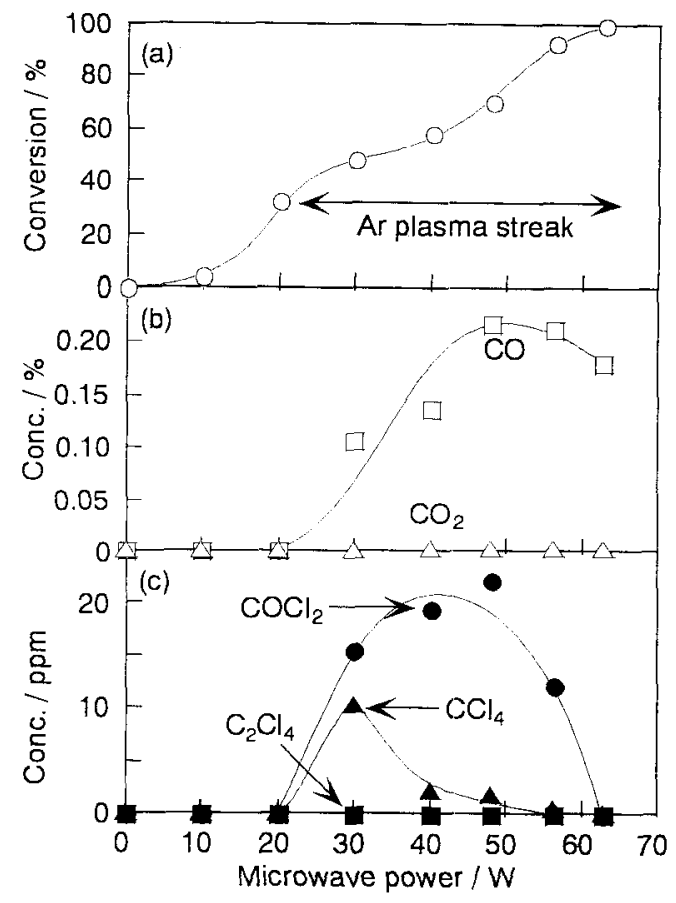

Fig. 5 Variations in (a) conversion of trichloroethylene and in (b) and (c) concentration of partial decomposition products in the MI Ar plasma decomposition with the microwave power absorbed (feed gas: flowing Ar containing, $0.11 \%$ trichloroethylene and $0.38 \% \mathrm{H}_{2} \mathrm{O}$ ). as shown in Fig. 4(c). Thus, it is confirmed that thrichloroethylene can be decomposed completely by the MI Ar plasma of a microwave power higher than $70 \mathrm{~W}$ under the flowing Ar containing $0.11 \%$ trichloroethylene and $9.0 \% \mathrm{O}_{2}$.

3.2.2 Decomposition behavior of trichloroethylene under an atmosphere containing water vapor

In contrast to the above two cases, the MI Ar plasma streak could be generated upon irradiation of a microwave power as low as $20 \mathrm{~W}$ under the flowing Ar containing $0.11 \%$ trichloroethylene and $0.38 \%$ water vapor. However, the conversion was very low at $20 \mathrm{~W}$, as shown in Fig. 5(a). The conversion increased gradually with increasing the microwave power, and then reached almost $100 \%$ at $60 \mathrm{~W}$. A large amount of $\mathrm{CO}$ was produced and formation of $\mathrm{CO}_{2}$ was rarely found even at the $100 \%$ conversion level, as shown in Fig. 5(b). These results confirm again that water vapor acts as a weak oxidizing agent in the MI Ar plasma. However, it was found that the concentration of partial decomposition products was lower than that shown in Fig. 3 or 4 . Especially, formation of $\mathrm{C}_{2} \mathrm{Cl}_{4}$ was rarely observed in the whole range of the microwave power tested, as shown in Fig. 5(c). Water vapor might accelerate the oxidation of the partial decomposition products or promote a different decomposition route of trichloroethylene. Another possibility is that partial decomposition

Table 1 Decomposition behavior of trichloroethylene (TCE).

\begin{tabular}{|c|c|c|c|c|c|c|c|c|}
\hline \multirow[t]{2}{*}{ Method } & \multirow[t]{2}{*}{ No. } & \multicolumn{3}{|c|}{ Concentration $(\%)$} & \multirow{2}{*}{$\begin{array}{l}\text { MW power for } \\
100 \% \text { conversion } \\
\text { of TCE (W) }\end{array}$} & \multirow{2}{*}{$\begin{array}{l}\text { Complete } \\
\text { oxidation } \\
\text { (no } \mathrm{CO} \text { ) }\end{array}$} & \multirow{2}{*}{$\begin{array}{l}\text { Maximum } \\
\text { concentration of } \\
\mathrm{COCl}_{2}(\mathrm{ppm})\end{array}$} & \multirow{2}{*}{$\begin{array}{l}\text { MW power } \\
\text { for } 5 \text { ppm } \\
\text { decomposition } \\
\text { products (W) }\end{array}$} \\
\hline & & TCE & $\mathrm{O}_{2}$ & $\mathrm{H}_{2} \mathrm{O}$ & & & & \\
\hline \multirow[t]{7}{*}{ Plasma } & 1 & 0.11 & 3.0 & 0 & 50 & No & $65(50 \mathrm{~W})$ & $>80$ \\
\hline & 2 & 0.11 & 9.0 & 0 & 50 & Yes $(>60 \mathrm{~W})$ & $50(50 \mathrm{w})$ & $>70$ \\
\hline & 3 & 0.11 & 0 & 0.38 & 62 & No & $25(50 w)$ & 63 \\
\hline & 4 & 0.11 & 0 & 0.77 & 70 & No & $12(50 \mathrm{~W})$ & $>75$ \\
\hline & 5 & 0.11 & 3.0 & 0.38 & 50 & Yes $(>80 \mathrm{~W})$ & $80(60 w)$ & $>80$ \\
\hline & 6 & 0.23 & 9.0 & 0 & 60 & Yes $(>100 \mathrm{~W})$ & $210(50 \mathrm{w})$ & 80 \\
\hline & 7 & 0.64 & 9.0 & 0 & 60 & $\operatorname{Yes}(>90 \mathrm{~W})$ & $245(60 \mathrm{~W})$ & 80 \\
\hline \multirow[t]{2}{*}{ Thermal } & 8 & 0.11 & 3.0 & 0 & $50^{1)}\left(680^{\circ} \mathrm{C}\right)$ & No & $200(60 \mathrm{w})$ & 100 \\
\hline & 9 & 0.11 & 0 & 0.38 & $93^{1)}\left(930^{\circ} \mathrm{C}\right)$ & No & $4(70 w)$ & 102 \\
\hline
\end{tabular}

1) Electric power consumed by electric furnace. 


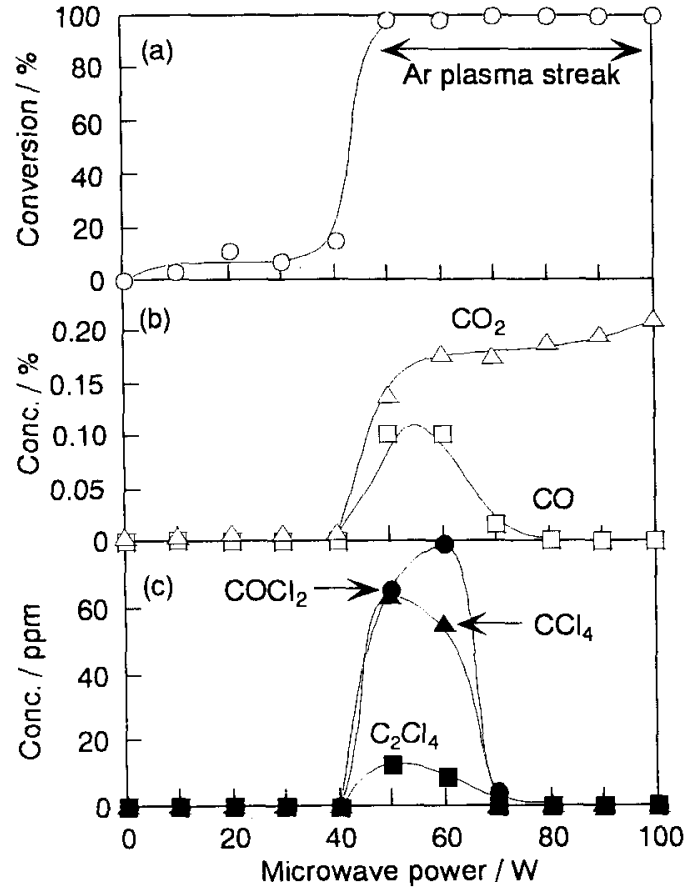

Fig. 6 Variations in (a) conversion of trichloroethylene and in (b) and (c) concentration of partial decomposition products in the MI Ar plasma decomposition with the microwave power absorbed (feed gas: flowing $\mathrm{Ar}$ containing $0.11 \%$ trichloroethylene, $3.0 \% \mathrm{O}_{2}$ and $0.38 \% \mathrm{H}_{2} \mathrm{O}$ ).

products likely dissolve in water condensed at some parts in the flow apparatus, though the details are not clear at present.

Almost the same results as above were obtained when the concentration of water vapor was increased to $0.77 \%$. Typical features of the decomposition behavior of trichloroethylene under this condition are summarized in Table 1. Results obtained under other decomposition conditions are also summarized for easy comparison. The conversion reached $100 \%$ at a high microwave power of $70 \mathrm{~W}$, but a large amount of CO (about $0.18 \%$ ) was detected. The concentration of partial decomposition products became lower at a microwave power of $50 \mathrm{~W}$ than other conditions: the maximum $\mathrm{COCl}_{2}$ concentration was $12 \mathrm{ppm}$ at 50 W. Therefore, the addition of water vapor alone is found not to be enough for achieving the complete oxidation of trichloroethylene.

3.2.3 Decomposition behavior of trichloroethylene under an atmosphere containing $\mathrm{O}_{2}$ and

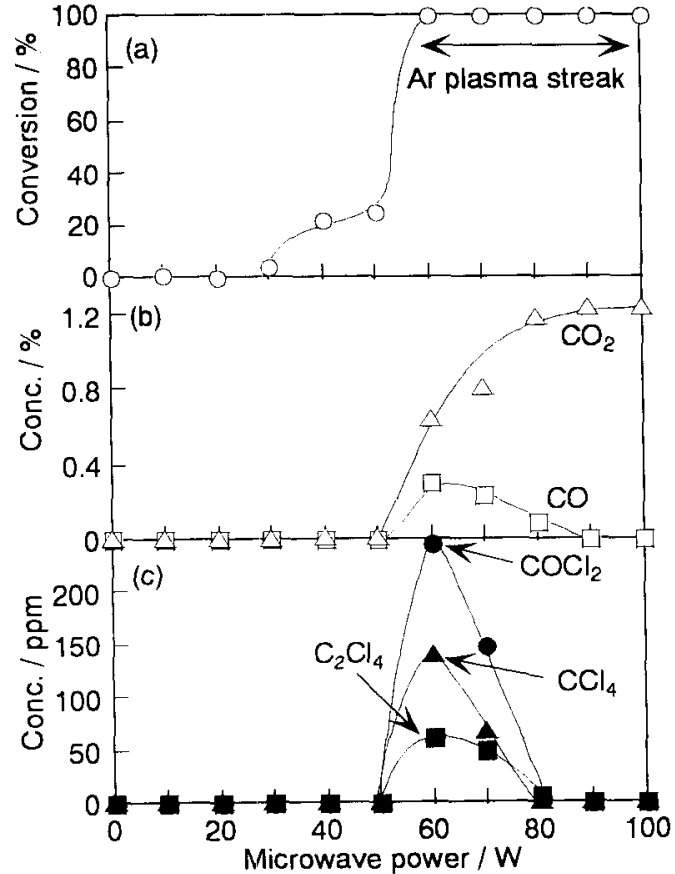

Fig. 7 Variations in (a) conversion of trichloroethylene and in (b) and (c) concentration of partial decomposition products in the MI Ar plasma decomposition with the microwave power absorbed (feed gas: flowing Ar containing $0.64 \%$ trichloroethylene and $9.0 \% \mathrm{O}_{2}$ ).

\section{water vapor}

Figure 6 shows decomposition behavior of trichloroethylene under the flowing Ar containing both $3.0 \% \mathrm{O}_{2}$ and $0.38 \%$ water vapor. The simultaneous addition of water vapor and oxygen did not effect significantly on the decomposition behavior, as compared with Fig. 3, the concentration of partial decomposition products being at a high level. Thus, the decomposition behavior could not be improved by the simultaneous addition of oxygne and water vapor.

\subsubsection{Decomposition behavior at a high trichloro- ethylene concentration level}

As summarized in Table 1, $0.23 \%$ and $0.64 \%$ tricholoethylene could be decomposed completely above $100 \mathrm{~W}$, provided that the flowing Ar contained $9.0 \% \mathrm{O}_{2}$. No $\mathrm{CO}$ and partial decomposition products were observed above $90 \mathrm{~W}$, in spite of the high trichloroethylene concentration, as typically shown in Fig. 7. A common feature observed with the high trichloroethylene concentration is the formation of 


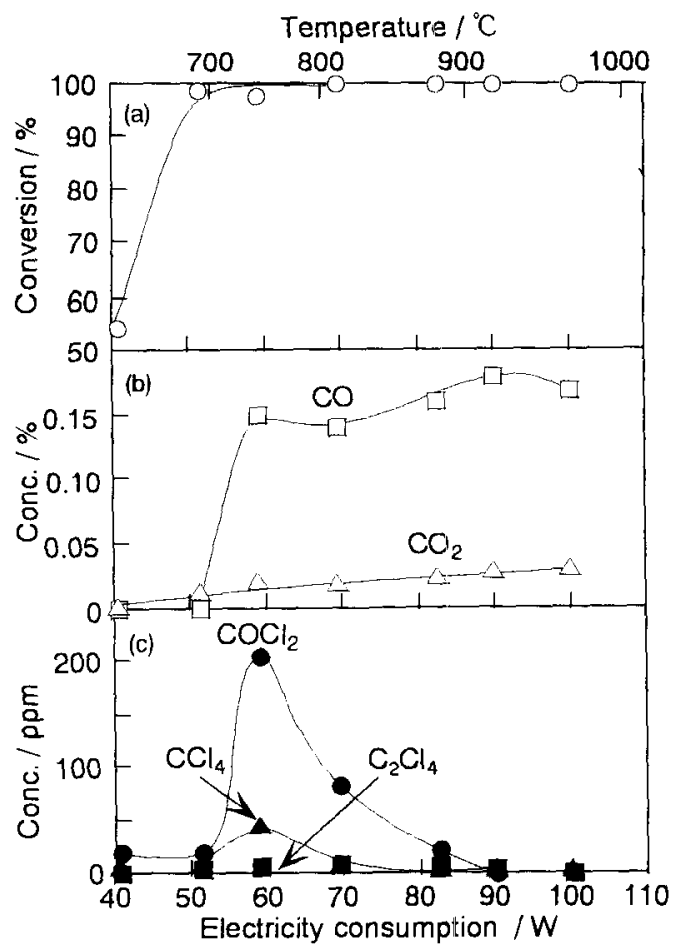

Fig. 8 Thermal decomposition behavior of trichloroethylene over SiC ceramics. (a) Conversion of trichloroethylene and in (b) and (c) concentration of partial decomposition products of trichloroethylene (feed gas: flowing $\mathrm{Ar}$ containing $0.11 \%$ trichloroethylene and $3.0 \% \mathrm{O}_{2}$ ).

partial decomposition products in large quantities around a microwave power of $50-60 \mathrm{~W}$. This tendency was further pronounced when only $3.0 \% \mathrm{O}_{2}$ was added to the flowing Ar, though the data were not cited in Table 1 . If the microwave power is high and enough oxygen is added to the flowing Ar, however, it is confirmed that the high trichlorcethylene concentration can be completely decomposed by the MI Ar plasma.

\subsubsection{Thermal decomposition of trichloroethylene}

Conversion of trichloroethylene and concentration of partial decomposition products after thermal decomposition over SiC ceramics are plotted against the power consumed by the electric furnace used for heating the ceramics, as shown in Fig. 8. Since the temperature of the decomposition zone is a function of several factors, such as the size of the furnace, the flow rate of gases and so on, it is difficult to directly compare the power consumption between the thermal decomposition and the MI Ar plasma decomposition. However, the power consumed by the furnace and the temperature of the furnace attained are indicated in the lower and upper abscissa, respectively, for reference. In this case, the conversion reached almost $100 \%$ at a power consumption of $50 \mathrm{~W}$, i.e. around $700^{\circ} \mathrm{C}$. In contrast to the case of the $\mathrm{MI} \mathrm{Ar}$ plasma decomposition shown in Fig. 3, a large amount of $\mathrm{CO}$ was produced by the thermal decomposition, and only a small amount of $\mathrm{CO}_{2}$ was produced. It was also revealed that considerable amounts of partial decomposition products were formed by the thermal decomposition. When $0.38 \%$ water vapor was added, instead of $3.0 \% \mathrm{O}_{2}$, much higher electric power (about $90 \mathrm{~W}$ ) was necessary to achieve $100 \%$ conversion, as summarized in Table 1. Even at a $100 \%$ conversion level, about $0.2 \% \mathrm{CO}$ was produced and no $\mathrm{CO}_{2}$ was observed, whereas the concentration of partial decomposition products was less than 1 ppm. These results confirm the potential advantage of the $\mathrm{MI} \mathrm{Ar}$ plasma generated from $\mathrm{SiC}$ ceramics for decomposing thrichloroethylene under atmospheric pressure with relatively low energy consumption.

\section{CONCLUSION}

It was confirmed that $\mathrm{MI}$ Ar plasma could be generated from $\mathrm{SiC}$ ceramics in flowing $\mathrm{Ar}$ containing trichloroethylene, oxygen and/or water vapor under atmospheric pressure. The analysis of decomposition behavior has revealed that trichloroethylene could be completely decomposed by the MI Ar plasma in the flowing Ar containing an appropriate amount of oxygen. In addition, $0.64 \%$ trichloroethylene balanced with Ar at a flow rate of $500 \mathrm{~cm}^{3} \mathrm{~min}^{-1}$ could be completely decomposed by the addition of $9.0 \% \mathrm{O}_{2}$ upon irradiation of microwave higher than $90 \mathrm{~W}$, without producing any partial decomposition products as well as $\mathrm{CO}$. In contrast, a large amount of $\mathrm{CO}$ was formed by the thermal decomposition of trichloroethylene even at a temperature as high as $900^{\circ} \mathrm{C}$. Thus, the decomposition by the MI Ar plasma is confirmed to offer several advantages, compared with the thermal decomposition, with respect to complete oxidation, concentration of partial decomposition products and energy efficiency. Since the MI Ar plasam generated in this study was a streak like and was not spread out in the quartz glass tube, it is anticipated that the gaseous molecules of trichloro- 
ethylene are not enough in contact with the MI Ar plasma. Therefore, further improvement in decomposition efficiency is possible by controlling the MI Ar plasma condition in future.

This study was partially supported by a Grant-inAid for Scientific Research from the Ministry of Education, Science, Culture and Sports of Japan.

\section{References}

1) T. Oda, T. Takahashi, H. Nakano and S. Masuda, IEEE Trans. Ind. Appl., 29, 787 (1993).

2) A. Kohchi, S. Adachi and Y. Nakagawa, Jpn. $J$. Appl. Phys., 35, 2326 (1996).

3) M. E. Fraser, D. A. Fee and R. S. Sheison, Plasma Chemistry and Plasma Processing, 5, 163 (1985).

4) M. Koch, D. R. Cohn, R. M. Patrick, M. P. Schuetze, L. Bromberg, D. Reilly, K. Hadidi, P.
Thomas and P. Falkos, Envion. Sci. Technol., 29, 2946 (1995).

5) M. C. Hsiao, B. T. Merritt, B. M. Penrtrante, G. E. Vogtlin and P. H. Wallman, J. Appl. Phys., 78, 3451 (1995).

6) K. Sugiyama, K. Tsutsumi and T. Matsuda, Denki Kagaku, 60, 1012 (1992).

7) M. Egashira, Y. Shimizu, Y. Takao and S. Sasada, Proc. of Intern. Symp. on Environmental Issues of Ceramics, Oct. 19-20, 1994, Sapporo, Japan (1995) p.185.

8) M. Egashira, Y. Shimizu, Y. Takao and M. Ono, Proc. of the 2nd Intern. Meeting of Pacific Rim Ceramic Societies, July 15-17, 1996, Cairns, Australia, in press.

9) M. Egashira, Y. Shimizu, Y. Takao, M. Ono and S. Sasada, J. Electrochem. Soc., 145, 229 (1998). 